\title{
Assessments of the Challenges of Hydrography and Accuracy of the Chart Information Based on Requirements on Nautical Charts in Tanzania
}

\author{
Joel Michael Ojode, Bian Hogwei \\ Department of Navigation, Naval University of Engineering, Wuhan, Hubei, 430033, China.
}

\begin{abstract}
Many of the electronic chart position deviations that observed today come from past graphic collecting techniques of Nautical Chart. This study introduces an assessment of the challenges of hydrography and accuracy of the chart information based on requirements on nautical charts in Tanzania. The assessment of the challenges of hydrography and accuracy of the chart information is particularly important to strengthen data accuracy and meet the requirement of nautical charts in Tanzania. Primary data were collected through face-to-face interviews with the respondents and questionnaires as a tool. Secondary data obtained through, journals, articles, and report both published and unpublished. Quantitative data were analyzed by using SPSS whereas qualitative data analyzed by using content analysis. Data provided in this article will improve nautical navigational charts practices in Tanzania and reduce variation greatly in accuracy to help mariners make informed decisions based on the data in their onboard navigation systems. The article is relevant to the new IHO guide on how to assess the accuracy and reliability of depth and position information in nautical navigation charts. The recommendations have been arranged that nautical charts, which offer much considerable information for the safe navigation of ships, are able to work more efficiently.
\end{abstract}

Key words: Hydrography, Chart Information, Nautical charts, Tanzania

1. Introduction

The situation concerning hydrography and nautical chart services in Tanzania, are demanded by the presence a long coastline on the Indian Ocean and inland water bodies. Tanzania has an obligation under international law to ensure the safety of navigation, and shipping activities, which is growing fast in the country. It is means number of ship arrival, and outbound the country's water are increases. If no improve in hydrographic data, it may lead to ship's emergencies or other maritime disasters. On the other hand, Tanzania is among of countries in East Africa that depends on maritime a key resource for her people is Tanzania. The sectors of marine contribute much to the level of economic of the individual, private sector as well as national level due to the numerous vessels navigating on the Tanzanian Indian Ocean and lakes such as cargo ships and passenger ferries from mainland to island. In 2017, SUMATRA established the Tanzania Shipping Agencies Corporation (TASAC), The reason behind establishment of TASAC was to regulate marine transport as well as shipping agencies in mainland Tanzania, by assuming the rights and responsibilities of SUMATRA. Tanzania Shipping Agencies Corporation (TASAC) became a selfregulating body in 2017 after the enactment of Tanzania Shipping Agency Act 2017 (Kasanda et al, 2018). Commercial ships, non-commercial ships and naval ship operating in domestic water, to carry nautical charts because they are essential tools for marine navigation, but the TASAC still have the challenges lead failures to update nautical chart information on Tanzania navigable water, which is the main concern of this article.

Furthermore, Portolans (nautical charts covered by a network) began to appear in Europe at the end of the thirteenth century (Campbell, 2018). This innovation took advantage of the new practical use of the magnetic compass for marine navigation. The invention of radio way result in the 1930s, which finally led to the adding of LORAN 
lattices on nautical charts, is another model, radical way; most notability, moving from paper media to the digital form of Electronic Navigational charts (EN)(Nicolai, 2015).

Recent technologies have made available paper charts which are printed "on demand" with cartographic data that has been downloaded to the commercial printing company as recently as the night before printing. Tanzania still faces problems of editing, revising and correcting maps, as there are no established a relevant institutions to do this work. In this case, the paper will assess the challenges and accuracy of the information in the nautical chart applied in Tanzania navigable water bodies. For advanced of the voyage the corrected versions in irrespective working with nautical chart or ECDIS, to assure the navigators updated chart information.

- Depending on the availability of the detailed area, on water bodies, such as a lake, harbor, ocean, bay, or shoreline, indicate the depth of the water and the features of the seabed.

- The charts also show the height and location of landmarks, such as islands or other landmasses, hills, radio towers, and buildings as well as provide detailed information about aids to navigationlighthouses, buoys, and other artificial markers that help navigators avoid shallow water and other perils.

\subsection{Nautical chart analysis in general}

Tanzania lacks national capability for nautical chart or publication production that carried out by the United Kingdom Hydrographic Office (UKHO) as the Primary Charting Authority (PCA). UKHO charting of Tanzania and its outlying islands is of variable quality relying, with notable exceptions in the main ports of Dar es Salaam and Zanzibar, on data between 90 and 130 years old. For historical reasons, the production of nautical charts and publications required under SOLAS, for Tanzania nautical chart produced by the UKHO. The United Kingdom Hydro graphic office (UKHO) is the main major organization dealing with upkeep of charts and numerous nautical publications. The hydrography of navy in United Kingdom is under the command of admiralty- an administrative authority commanding the Royal Navy. Most of many nautical charts in Tanzania published with (UKHO). However, there are others famous publishers such as Australian and New Zealand charts. The chart kept updated by hydrographic offices located in New Zealand Chart and Japanese charts also published by the admiralty under similar arrangement. They are two updated on the basic of information broadcasted by Japanese Hydro graphic offices. In fact, it is even difficult to determine the proportion of chart sales attributed to professional mariners verses recreational boaters, much less others using charts for any number.USA first established the survey of the coast in 1807, which reorganized in 1970 as part of National Oceanic and Atmospheric Administration (celebrating its 50th anniversary this year). (Reference) Over the centuries, paper charts grew in detail and complexity as the agency worked to keep step with coastal development. "Our charts are designed with the voyage in mind. The scale was often adjusted to fit all the details on a standard-sized sheet of paper. Paper navigational replaced by apps as quickly as paper road atlases were and both technology and international law played roles in the slower adoption.

Table 1 Hydrographic Resource in Tanzania

\begin{tabular}{|l|l|l|}
\hline Institute & Resources & Percentage \\
\hline $\begin{array}{l}\text { Hydrographic Survey Section, Surveys and } \\
\text { Mapping Division, }\end{array}$ & IHO Cat B level & $3 \%$ \\
\hline Tanzania Ports Authority & $\begin{array}{l}\text { IHO Cat B level and one at IHO } \\
\text { Cat A }\end{array}$ & $4 \%$ \\
\hline University of Lands and Architectural Studies & IHO Cat A hydrographer & $7 \%$ \\
\hline Tide gauge Network & $\begin{array}{l}\text { Satellite link to the University of } \\
\text { Hawaii. }\end{array}$ & $5 \%$ \\
\hline United Kingdom Hydrographic Office (UKHO & $\begin{array}{l}\text { hydrography of navy in United } \\
\text { Kingdom }\end{array}$ & $82 \%$ \\
\hline
\end{tabular}

Table 1 describe that Tanzania has a variety of hydrographic resources that raise awareness of national hydrography survey and its potential benefits to the economy of the country. Still the country has no sustainable chart correction because it lacks development process whereby survey processes within the country lack priority, finance (fund) and professional personnel in hydrographic, that why UKHO possess $82 \%$ of chart publication in Tanzania.It obligates 
Tanzanian Government use a lot of money to link with UKHO to ensure that new navigationally significant information is forwarded and included in existing charts of Tanzania which up now has failed and let many nautical chart in Tanzania to become un updated for long time. Those results into chart errors see Figure 2.

\subsection{The Common challenge of ECDIS over Nautical chart}

The popular of errors made on the (ECDIS) are in the user's interpretation of how the ECDIS displays information. The user given the freedom to present the chart in a number of ways: as such without a thorough understanding of how the system works, there may be some confusion in what the system in presenting. A cartographer, who has exceptional skill in arranging the chart in such a manner, that the mariner can clearly distinguish all the information necessary, draws nautical charts. Nautical charts come with a source diagram that explains when the chart surveyed. Nautical Chart dictated that during a voyage plan the navigator, would consult these charts and determines if the source data was adequate and how reliable, the soundings on the chart might be before proceeding with the passage. Paper chart pencils, divider, similar rules and protractors, as well as notice to Mariners and chart correction template, still used to chart. Crewmembers ordinarily fix their ship's position every ten minutes, or less often-in open Ocean.

\subsection{Mercator and Gnomonic projection charts challenge assessment in Tanzania}

Further analysis revealed that the two nautical charts that are available in Tanzania navigable area are Gnomonic and Mercator chart. The Mercator chart is the most common. Mercator chart, courses are used in all coastal navigation. Most of passage of ship operating in domestic is less than 200 miles. Due most ship sailing along the coastal they require Mercator chart which lead the less availability and high cost of purchase as described in Table 2 below.

Table 2 Type of Chart available in Tanzania's on-board ship

\begin{tabular}{|l|l|l|l|}
\hline Type of chart & Applications & Availability & Cost \\
\hline Mercator chart & Piloting (Distance measurement) & $35 \%$ & High \\
\hline Gnomonic charts & Great-circle determination & $65 \%$ & Low \\
\hline
\end{tabular}

Table 3Nautical chart cost and Publication analysis in Tanzania

\begin{tabular}{|l|l|l|l|l|l|}
\hline $\begin{array}{l}\text { Chart } \\
\text { No }\end{array}$ & Chart Name & Scale & $\begin{array}{l}\text { Cost } \\
\text { (USD) }\end{array}$ & Publication & $\begin{array}{l}\text { Latest } \\
\text { Edition }\end{array}$ \\
\hline 661 & Approach to Kilwa harbour & 75,000 & $\$ 42.15$ & Jane 1984 & Dec 2009 \\
\hline 663 & Approaches to Tanga & 37,500 & $\$ 41.75$ & Aug 1997 & ----------- \\
\hline 665 & Approaches to Zanzibar & 50,000 & $\$ 43.95$ & July 1995 & ----------- \\
\hline 674 & Approaches to Dar es salaam & 50,000 & $\$ 43.95$ & May 1983 & Dec 2000 \\
\hline 681 & Lindi Bay & 25,000 & $\$ 43.95$ & Aug 1982 & Dec 2009 \\
\hline 684 & Mtwara and Mikindani harbours & 36,286 & $\$ 41.75$ & May 1875 & Jan 1950 \\
\hline 690 & Cabo Delgado to Mikindani Bay & 72,800 & $\$ 43.95$ & May 1948 & ---------- \\
691 & Mtwara Harbour & 12,500 & $£ 26.40$ & & \\
\hline 693 & Dar es salaamharbor & 7,500 & $\$ 42.15$ & Feb 1983 & Apr 2005 \\
\hline 2927 & Pemba to Mtwara & 300,000 & $\$ 42.15$ & Dec 2002 & July 2012 \\
\hline 2929 & Mtwara to Mafia island & 350,000 & $\$ 42.15$ & Oct 2003 & ---------- \\
\hline 3211 & Zanzibar Harbour & 12,500 & $\$ 43.95$ & Apr 1986 & Oct1994 \\
\hline 3252 & Victoria Nyanza-north portion & 294,000 & $\$ 43.95$ & May 1902 & Feb 1956 \\
\hline 3310 & Mafia to Pemba island & 350,000 & $\$ 42.15$ & Aug 1997 & ------------ \\
\hline 3665 & Victoria Nyanza- southern portion & 294,000 & $\$ 44.95$ & Mar 1908 & Feb 1956 \\
\hline 3993 & Plans in lake Victoria Nyanza & $\ldots \ldots \ldots \ldots$ & $\$ 42.15$ & Sept 1908 & ----------- \\
\hline
\end{tabular}

Table 3describe common list of charts. Nautical charts in Tanzania mostly are out of date, buoys are moved, removed, or changed, shorelines shift, or new hazards not indicated. No changes to charts between publications and 
daily Notices to Mariners, nautical chart in Tanzania Indian Sea and Lake Victoria, many data information is not current updated. For example: nautical chart no. 2927 named Pemba to Mtwaralatest edition is July 2012 up to 2021 is about 9 years with no chart correction, results island size, and figures are not perfect. The chart published in London Dec 2002 still in use. For hesitance when navigating in the area closed to entrance of river to sea or lake it is likely to run the vessel into dangerous because the river come with a lot of debris. That may reduce the sounding of navigable sea area. Because Tanzania has many rivers that enter water into navigable areas, it is better to survey it always. See Table 4 gives some list of main rivers.

Table4. Main Rivers of Tanzania

\begin{tabular}{|l|l|l|}
\hline Rivers & Total Length & Entrance water body \\
\hline Nile & 4,258 miles & Lake Victoria. \\
\hline White Nile & 2,299 miles & Lake Victoria \\
\hline Ruvuma & 497 miles & Indian Ocean \\
\hline Rufiji & 373 miles & Indian Ocean \\
\hline Wami & 304 miles & Indian Ocean \\
\hline
\end{tabular}

\subsection{Paper chart analysis in Tanzania}

Figure 1 percentages demonstrate the coverage of the information in paper chart since 2012 to 2020. It reveals that there many details information on the chart which is not corrected/ update in difference passage. Due to the fact Tanzania, does not have a chart production capability and relies historically on the UKHO to fulfill the function of chart correction.

\section{Tanzania paper chart coverage region}

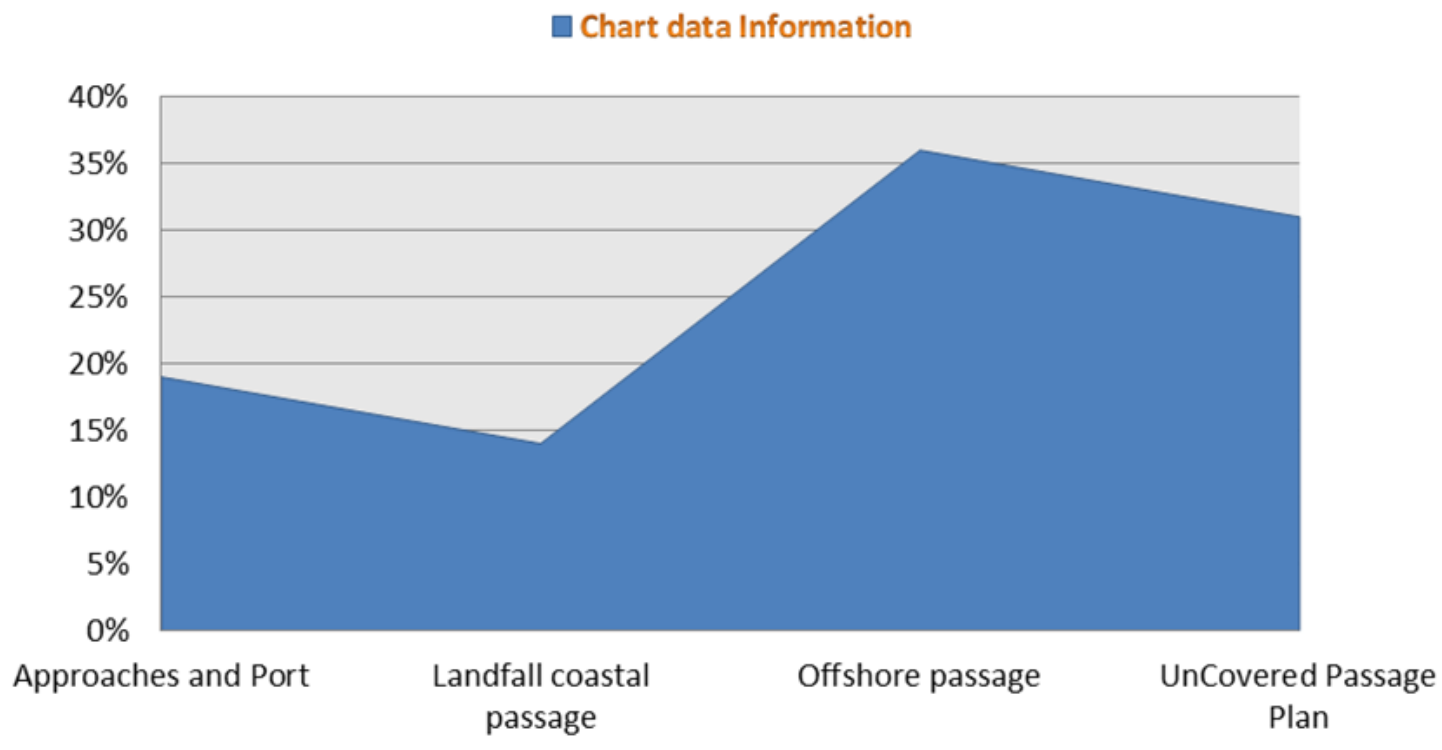

\section{Methodology}

Figure 1 Nautical chart demonstration analysis

The study employed the following data collection tools such as interviews, questioners, and review of different literature to obtained data. Purposively sampling was used to get hold of respondents who participated in interviews. The selection of respondents based on those who can provide detailed and reliable information on the subject under study. The study population complies staff of Dares Salaam Maritime Institute, Mbengani Fishing College, Tanzania's crews' onboard ship (navigators), TASU, and MNOAT. Whereas primary data were collected through face-to-face interviews with the respondents and questionnaires as a tool, Secondary data obtained through, journals, 
articles, and report both published and unpublished. Quantitative data analyzed by using SPSS whereas qualitative data analyzed by using content analysis. The issues of ethical considerations considered including getting consent of the respondents.

Table 5. Study sample distribution

\begin{tabular}{|l|c|}
\hline Organization & Sample (50) \\
\hline Dar es Salaam Maritime Institute(DMI) & 10 \\
\hline Mbengani Fishing Collage(MFC) & 10 \\
\hline Tanzania's crews' onboard ship (navigators) & 25 \\
\hline TASU & 5 \\
\hline MNOAT & 3 \\
\hline Total & $\mathbf{5 0}$ \\
\hline
\end{tabular}

Table 6 Random sampling distribution

\begin{tabular}{|l|c|c|}
\hline Type of respondent & Number of respondents expected & No Interviewed \\
\hline DMI & 10 & 7 \\
\hline MFC & 10 & 6 \\
\hline Navigators & 15 & 13 \\
\hline TASU & 5 & 4 \\
\hline MNOAT & 10 & 5 \\
\hline Total & 50 & 35 \\
\hline
\end{tabular}

The survey anticipated collecting data from 50 respondents. However, data collected from 35 out of 50 respondents, representing $70 \%$ of the projected number of respondents. About the working experience of the respondents, the study was able to get data on their experience within their organization in order to get relevant information from different group of employees. Both groups have different period of working experience, the one with long experience, we're able to provide information deeply by using relevant examples while those with short experience.

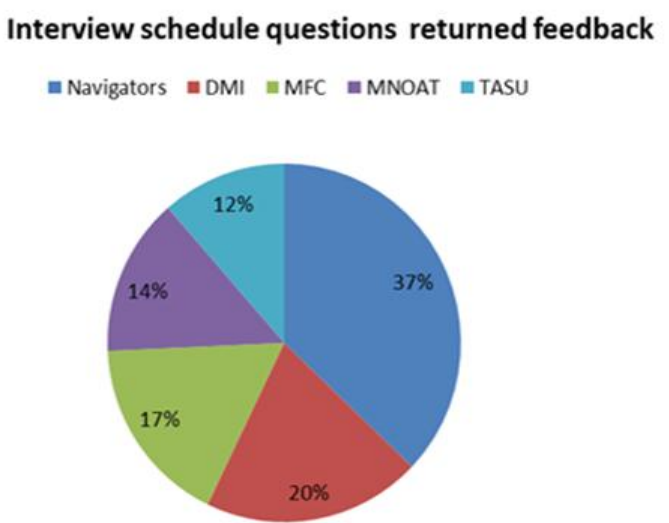

Figure 2Interview percentage returned number of maritime stakeholders in Tanzania

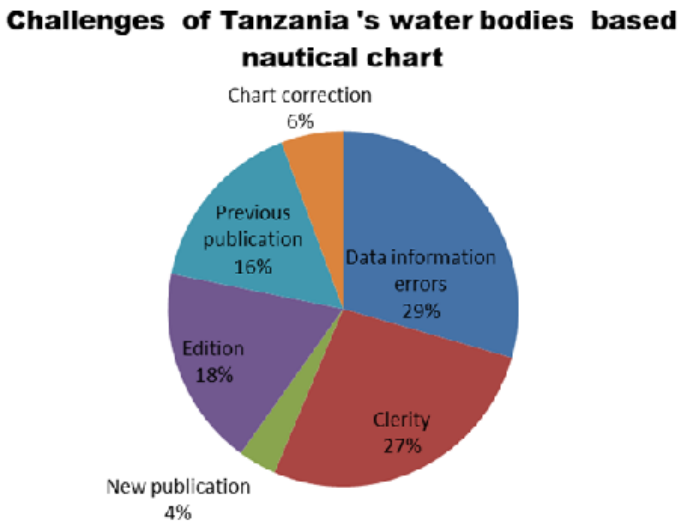

Figure 3Percentage of Challenges of navigable water bodies.

\subsection{Findings and discussions}

This section provides the feedback that the interviews, respondent background information, analysis, and interpretation of the results provided through text, tables, and figures. The study provides a detailed overview of the 
uses of nautical chart in adoption to contemporary digital technology advancing nautical chart and suggestion for future expansion. Discussions focused on improving the reliability and efficiency of paper-based maps in Tanzania. The study population formulated relevant policies to promote the development of work relevant to safe navigation in the shipping sector. Further analysis revealed that some charts are not clear information and have many errors that endanger the lives of passengers, cargo, ships, and persons working on board ships. The responses analyzed point to the need to consider the use of currently updated navigation in each voyage. The findings of the surveyed population are accompanied by summaries of the following challenges, see table 7 below.

Table 7 summary of challenges

\begin{tabular}{|l|l|}
\hline Technical Challenges & $\begin{array}{l}\text { Resources Challenges/ correction nautical chart in } \\
\text { Tanzania }\end{array}$ \\
\hline Date information error & Lack of priority in dealing with updated nautical chart \\
\hline Lack of competent staff in Hydrographic survey & Uses of traditional navigation \\
\hline Lack of enough technology in hydrographic data & $\begin{array}{l}\text { Lack of printing machine for printing updated nautical } \\
\text { chart }\end{array}$ \\
\hline $\begin{array}{l}\text { Use of incompetency regulatory bodies in maritime } \\
\text { matter based in safety of navigation }\end{array}$ & $\begin{array}{l}\text { Lack of profession hydrographic personnel(currently } \\
\text { there Three in the whole country) }\end{array}$ \\
\hline $\begin{array}{l}\text { Lack of intervene international organization to carry } \\
\text { out survey in inland waters }\end{array}$ & Negligence and trial and error navigation \\
\hline $\begin{array}{l}\text { Lack of hydrographic survey office to carry out the } \\
\text { relevant work }\end{array}$ & High Cost of printing nautical chart \\
\hline Deficit of hydrographic expert & Lack of budget to deal with chart update \\
\hline $\begin{array}{l}\text { Confusion of safety water to navigate the ship in } \\
\text { shallow area because of lack of currently updated } \\
\text { chart }\end{array}$ & $\begin{array}{l}\text { Lacking in-country Maritime Safety Information } \\
\text { training }\end{array}$ \\
\hline $\begin{array}{l}\text { Many nautical charts are copy of the original chart } \\
\text { which of lack some importance information most of } \\
\text { them lacking accuracy information for fix the ship } \\
\text { position }\end{array}$ & lacks any hydrographic equipment \\
\hline
\end{tabular}

\subsection{Chart Correction analysis in Tanzania}

Tanzania has many numerous numbers of ship accidents, which resulted the ship to sink, currently sank ship in Lake Victoria, and in the Indian Ocean (Please see below tables 8). The position of sinking had not been recognized and indicated on nautical chart as wreck showing any portion of the hull or superstructure above datum of sounding not drawn to scale or drawn according to hulls actual position and direction; firm line representing the above-water portion. Failures to recognize the position of the sinking left the gap in the nature of the accident and its cause and hence create the gaps in the future control of the accident. Therefore, the accident control strategy needs an in-depth analysis of the past scenario; otherwise, it will lead to non-scientific projections.

Table 8 list of ship sank in sea and lakes in Tanzania

\begin{tabular}{|l|c|c|}
\hline \multicolumn{1}{|c|}{ Vessel } & Years & Events \\
\hline M.V Bukoba & 1996 & Capsized \\
\hline M.V Kabelega & 2005 & Sank \\
\hline M.V Thor & 2006 & Ground \\
\hline M.V Nyamageni & 2006 & Capsized and sank \\
\hline Passenger boat & 2010 & Capsized \\
\hline
\end{tabular}




\begin{tabular}{|l|c|c|}
\hline M.V Nyerere & 2018 & Capsized \\
\hline M.V Islander 1 & 2011 & Sank \\
\hline M.V Skagit & 2012 & Capsized \\
\hline M.V Alafatt & 2013 & Electrical fire \\
\hline
\end{tabular}

Accordingly, the study observed that, many ships have sunk in Tanzania bodies of water and are not collected (updated) in the nautical map and in which position/location in the navigable waters in Tanzania.

\section{"More than six ships and many small vessels, but some of them are not updated nautical charts for chart corrections are not reported, but many are reported are not updated for hydrographic use to be promulgated in notice to mariners".}

The failure to obtain the basis on accident causalities has encroached on efforts in preventative strategies that lead to the repetition of the same. For example, between 2011 and 2012 in the Indian Ocean of Tanzania, there was an accident involving M.V Islander I and M.V Skagit respectively. The same observation occurred in Lake Victoria where M.V Kabelega (2005) and M.V Nyamageni were sunk in two consecutive years. Consequently, with all the equipment on board ships today, there has to be the requisite training, mentoring, knowledge, skills, attentiveness and management to ensure this is used to the maximum benefit. Teamwork on board has never been more important and nor has situation awareness and the critical need to fully understand the resources at the Navigator's disposal. Meanwhile, the challenges that observed in chart corrections can be reduced by having competent personnel who will observe vessel traffic services and sea traffic management, coupled with yet more restricted areas for navigation. Safe draught is another feature, which must be foremost in a master's mind before and during the prosecution of a voyage. So often ships have run aground during river transits, while berthing and un-berthing, when dragging anchor or even on passage steering a course into shallow water believing there to be adequate under-keel clearance. Vessel traffic services (VTS) are an important aid, which, if used properly, enhances the safety of navigation into and out of ports and harbours, estuaries and in coastal areas with serious traffic thickness such as the Dover Strait. Clear and concise channels of communication between ship and shore, with alert, competent navigators and the appropriate aids to navigate a ship safely, are crucial ingredients to manage and reduce risk (Baker, et. al., 2003). There are lacking of symbols that do not available in Tanzania nautical chart to indicate the ship listed in Table 4, sunk in different area zone of navigable water for the safety of navigation. The assessment show that the processes of chart update in the country is still a problem that requires immediately solution to resolve these challenges for sustainable future safety navigation in Tanzania.

\section{TASAC Regulatory bodies, Regulation of Maritime Environment, Safety and Security}

In 2001, the Surface and Marine Transport Regulatory Authority (SUMATRA) was established as a multi-sect oral regulatory agency, under the Surface and Marine Transport Regulatory Authority Act 2001, to regulate rail, road, and maritime transport services in Tanzania.

- $\quad$ administer the Merchant Shipping Act 2003

- regulate and approved marine services, safety tools and marine services providers;

- regulate ferries;

- coordinate maritime search and rescue operations;

The article reveals that TASAC should provide, establish, and improve enforcements of laws and regulations enhancing uses and awareness of chart correction and understanding among the stakeholders through having updated chart. TASAC should come with the policy that will oversee all update maritime nautical charts in Tanzania and the associated with hydrographic survey to make sure they are currently updated. In addition, strong investment in maritime sector especially increasing the use of modern digital electronic chart equipment for safety of navigation at sea to all ships operating within our waters (domestic and international flying) should carry out updated nautical chart as primary back up of electronic chart in case of breakdown. The TASAC through MRCC they are dealing directly with chart correction information, but they lack capacity and professional hydrographs to the promotion of chart correction information. The review of the policy which no longer applicable, and establishment of new policy. 
This especially will increase number of hydrographic professional. In these, case of review shall be a full policy guiding which will enable hydrography body to have power/authority to stand alone to carry out this appropriate work and monitor the regulatory body. The organisation through hydrograph established should be able to provide new navigational warning and aids that can be buoys or wherever must inform TASAC/MRCC so that TASAC will update that information to UK.

Contrary to the above, the opinions of many participants did not agree on the existence of regulatory bodies like those that TASAC can contribute to the promotion of chart collection information in nautical chart based in Tanzania navigable water. A more in-depth analysis of TASAC's effectiveness reveals the need for a dedicated department to oversee all matters relating to hydrographic information.

\section{They must have special department to supervise all matters concerning hydrographic information.}

\section{Hydrography and Nautical Chart analysis}

The government of the Tanzania is a State Party to the SOLAS Convention and appears well versed with the provisions in SOLAS Chapter V Regulations 9 and 4 to ensure, that appropriate hydrographic and charting services made available. Hydrographic Committee (NHC) that its main work is nautical charting in Tanzania and its potentially adverse impact on safety of navigation. Despite of the requirement of SOLAS this vital component of national hydrography not working professionally due to the challenge discussed in the previous paragraph, should be considered as a high priority.

Yet there has been a problem of policy for hydrographic information. The policy needs to be well informed of all relevant procedures and information regarding hydrography in Tanzania. When asked whether it was necessary to review the policy that guides the chart on hydropower in Tanzania, one participant answered this question.

"If that is not the casing, I believe that there is a rule on hydrographic information and that, if it is the case, this rule must be reviewed and implement".

Adding to the above discussion, another participant elaborated his opinion in the following manner:

"Appropriate measure is to have the policy to guide the authorities on all matters concerning charts, to make sure all accidents events and all structures in our waters are reported and updated for charts correction".

The above statement revealed that the country needs to have policy that will regulate different practices of authorities that dealt with charts. The policy will strengthen and regulate the overall activities of nautical charts and update information for periodically basis for charts correction. This will clearly show all accident events and all structures in our water bodies. While the government is keen on attracting businesspersons and investors to use the Dar es Salaam port, this achieved by doing away with challenges they face at the port. In connection to the above views, the policy will be the base in the improvement of the water transport in Tanzania and make it safe for the users.

The author observed that sources of nautical charts in Tanzania normally depends on Hydrographic office in Tanzania Ports Authority (TPA) and charts importation from U.K. Having one source of nautical charts limit the easily accessibility and timely in case of highly demand. My anonymous informant demonstrated to me about the sources of nautical charts in Tanzania.

"We do not have the sources for nautical charts is Tanzania normally we depend on Hydrographic office in TPA, but they are also depends to import the charts from U.K”" 
In modern times, critical analysis needed when adapting equipment or technology used in the country. Procedures for obtaining marine charts to meet Tanzanian requirements require competent official suppliers.

\section{"We do not have an official nautical chart supplier/provider; therefore it's important for the authority to encourage suppliers of nautical equipment to start this kind of business to facilitate safe navigation in our water."}

Nowadays, seaports need highly developed technology system to be managed efficiently. Information systems have become essential to the competitiveness of ports, facilitating communication, and decision-making to enhance the visibility, efficiency, reliability, and safety of port operations under various conditions. It is increasingly important to provide value-added information and analysis services to maintain competitive advantage and meet regulatory requirements. Therefore, it is necessary to study the present information systems, both from an academic and practical point of view.

\subsection{Review of Preceding Technical visits Assessment}

The recommendations that have been made and the failures percentage in implementation to Tanzania as summarized under the key directions below in Table 6 with an assessment of development made with each item.

Table 9: Assessment of the development made

\begin{tabular}{|l|c|}
\hline Key directions & Percentage \\
\hline National Hydrographic Committee & $25 \%$ \\
\hline National Hydrographic Strategy & $36 \%$ \\
\hline Regional Hydrographic Commission Membership & $16 \%$ \\
\hline Maritime Safety Information & $10 \%$ \\
\hline National Hydrographic Capability & $13 \%$ \\
\hline
\end{tabular}

As it is shown in table 9 above, revealed a high percentage of failure in the national hydrographic strategy for about 36 percent, whereas 25 percent indicates failure in national hydrographic committee, 16 percent failure regional hydrographic commission membership. Further analysis revealed that the national hydrographic capability had a 13 per cent failure and that 10 per cent of the failure was in marine safety information.

\subsection{Tanzania Ports Authority (TPA)}

The Tanzania Ports Authority (TPA) is responsible for managing the entire Tanzanian mainland, maritime ports and lake ports, TPA promotes the effective management and operations of sea and inland waterway ports, and maintains ports safety in addition, and TPA has a hydrography section to undertake the following points, which had not achieved due to lack of capability. Even Zanzibar Ports Corporation (ZPC) is the responsible authority for the Zanzibar and Pemba harbors; it has no hydrographic capacity as well. TPA has several responsibilities including hydrographic surveys in seaports and inland waterways ports on Lakes victoria, Tanganyika and Nyasa. Also, other tasks includes; mmaintenance and improvement of marine navigational aids in seaports, coast and inland waterways ports, dredging to maintain depths at channels and berths in seaports and inland waterways ports, notices to mariners and conducting oceanographic studies.

In the light of the above understanding, there are needs of immediate safety of navigation and chart collection in the Tanzania maritime transport sector in Tanzania. This urgent need restructures the nautical chart provision required in order to solve problems associated with hydrographic information.

"I think should not be an investment for business perspective but should be an urgent service to cater for the nautical chart provision, hydrographic information collection in all our water bodies and routine promulgation of all matters concerning safety navigation should be reported and updated ASAP”. 
Adequate hydrographic information facilitates effectiveness and efficiency of the activities of ports and the profitability of shipping lines. Therefore, it is important for the government to conduct hydrographical survey regular in order to improve safety and avoid prevented accidents that can arise. It is therefore important that the government to consider policies that would improve the hydrographic information.

\section{Conclusion}

Tanzania lacks a well-defined policy system for the regulation and guideline of the hydrography and nautical charts. This is largely due to the high level of importance of the development of nautical chart by considering the new information raises in sea and lakes by establishing NHC to carry out the relevant activities as a requirement under the SOLAS Convention. Similarly, navigation aids are only as good as the user and will be in constant need of an alert observer who understands the input and output. Can assess the data provided and identify faults. As illustrated in the findings and discussions section the navigator needs to play an important role in ensuring the safeties of the water transport. The article advised that the current and updated chart is the core of the safety of navigation in Tanzania water bodies. Similar studies can be done but focusing on the factors affecting efficiency of navigation chart systems.

The author urges the government to mainstream nautical charts to national education system.DMI should train its students by providing the necessary maritime updated chart facilities manner in order to make maritime transport comfortable, efficient and reliable for both passengers and cargo ship application of nautical chart should give the positive image of Tanzania to the rest of the world. This requires more advanced policies, regulations, and should conduct a preliminary establish relevant institutions to carry out this work or formulate relevant policies to promote the development of relevant work available at our water bodies for the betterment of future generation. In the right of the above understanding TASAC must establish task forces to collect current information to all navigable water in Tanzania and updates the information to UK so that new nautical chart can be produced.

In conclusion, Tanzania is the grateful to produce her printing nautical chart machine and train personnel on hydrographic survey. She should establish institutes or the hydrographic office board that will carry out chart correction and survey of relevant the navigable waters in Tanzania, to control the safety navigation for the people, vessels as well as cargoes. Meanwhile Tanzania is the major, maritime influence in East Africa, she must pursue close support from UKHO and other related hydrographic survey companies such as U. S,Japanese Hydro graphic offices, Australian and New Zealand charts to reach at that scope. Therefore, We argue in this article, the government is obliged to allocate resources to formally designate a National Hydro graphic Authority to be responsible for coordination and ensuring the provision of appropriate nautical chart meet requirements of the International Convention on the Safety of Life at Sea (SOLAS), and in accordance with the principles established by the IHO, strengthen, and formalize the authority of the National Hydro graphic Board within the Tanzanian government structure. This article recommends developing and monitoring a coordinated training plan such that the IHO Cat B surveyors - from whichever department - can gain the necessary professional experience.

6. References

[1] Baker, Clifford C and McCafferty Denise B. ABS Review and Analysis of Accident Databases, 2003

[2] Campbell, Tony. "'Portolan charts from the late thirteenth century to 1500'"Map History / History of Cartography: THE Gateway to the Subject. Retrieved 8 December 2018. charthttps://iho.int/uploads/user/Services\%20and\%20Standards/NCWG/MISC/Future_of_the_Paper_Nautical_Chart_Preliminary(17 January 21)

[4] Maro Car, David Brčić, Srđan Žuškin, Boris Svilicic. (2020) The Navigator's Aspect of PNC before and after ECDIS Implementation: Facts and Potential Implications towards Navigation Safety Improvement. Journal of Marine Science and Engineering 8:11, pages 842.

[5] The East Africa (n.d): Ferry Disaster Turn focus to Lake Victoria Safety: Retrieved; May27,020:https://www.theeastafrican.co.ke/news/ea/Ferry-disaster-turns-focus-to-Lake-Victoria safety-4552908-4772178-1 
[6] Department of Commerce National Oceanic and Atmospheric Administration (2019) U.S. Chart No. 1 Symbols, Abbreviations and Terms used on Paper and Electronic Navigational Charts,

[7] IHO Capacity Building Programme (2012) The State of Hydrography and Nautical Charting in The United Republic of Tanzania

[8] Sidaevum (2017) Advanced Ocean Navigators: https://sidaerum.com/mod_16 (20/01/2021)

[9] Esri Blog NOAA (2020) The Digitalization of Navigational Charts for Safety, Efficiencyhttps://www.esri.com/about/newsroom/blog/noaaadvances-electronic-navigational-charts/

[10] Coastal navigation. Com (n d) The Nautical Chart http://www.coastalnavigation.com/samples/sec_1/1_pages/1_3.htm(20/01/2021)

[11] Nicolai, R. (2015). The Premedieval Origin of Portolan Charts: New Geodetic Evidence. Isis, 106(3), 517-543. doi:10.1086/683532 